\title{
Long-Term Statin Treatment in Children with Familial Hypercholesterolemia: More Insight into Tolerability and Adherence
}

\author{
Marjet J. A. M. Braamskamp • D. Meeike Kusters • \\ Hans J. Avis · Ellen M. A. Smets • Frits A. Wijburg • \\ John J. P. Kastelein · Albert Wiegman · Barbara A. Hutten
}

Published online: 3 February 2015

(C) The Author(s) 2015. This article is published with open access at Springerlink.com

\begin{abstract}
Background Statins are currently the preferred pharmacological therapy in individuals with familial hypercholesterolemia $(\mathrm{FH})$ with the aim to prevent premature atherosclerosis. In adults, these agents have been proven to be safe and well tolerated; however, non-adherence is a significant clinical issue.

Objectives In this study, we evaluated tolerability and adherence to statin therapy in young adult FH patients 10 years after this was initiated in their childhood.

Methods A questionnaire including items on medical history, adherence and reasons for discontinuation was sent to 214 young adult $\mathrm{FH}$ patients that initiated statin therapy at least 10 years ago. Tolerability was defined as $100 \%$ minus the percentage of patients that discontinued statin
\end{abstract}

M. J. A. M. Braamskamp (凹) · D. M. Kusters .

H. J. Avis - J. J. P. Kastelein

Department of Vascular Medicine, Academic Medical Center,

Meibergdreef 9, 1105 AZ Amsterdam, The Netherlands

e-mail: j.a.braamskamp@amc.uva.nl

M. J. A. M. Braamskamp · D. M. Kusters .

H. J. Avis · F. A. Wijburg - A. Wiegman

Department of Pediatrics, Academic Medical Center,

Amsterdam, The Netherlands

E. M. A. Smets

Department of Medical Psychology, Academic Medical Center,

Amsterdam, The Netherlands

B. A. Hutten

Department of Clinical Epidemiology, Biostatistics and

Bioinformatics, Academic Medical Center, Amsterdam,

The Netherlands therapy due to side effects. Adherence was defined as the extent to which patients took their medication as prescribed by their physician. We labelled patients adherent if they took $80 \%$ or more of their pills in the month preceding our assessment.

Results Follow-up was successful in 205 (95.8\%) subjects (age 18-30 years). A history of side effects was reported by $40(19.5 \%)$ of the patients, and mainly consisted of muscle complaints and gastrointestinal symptoms. Three patients $(1.5 \%)$ discontinued statin therapy because of side effects. Rhadbomyolysis or other serious adverse events were not reported. In fact, $169(82.4 \%)$ of 205 patients remained on statin treatment and $78.7 \%$ (148 out of 188) were adherent. None of the patient characteristics were significantly associated with adherence.

Conclusions Individuals with FH who started statin therapy in childhood demonstrated good adherence during ten years of treatment. Furthermore, statin therapy was well tolerated; only a small minority discontinued therapy because of side effects and the side effects that were reported were mild in nature.

\section{Key Points}

Subjects with familial hypercholesterolemia continuing statin therapy since childhood showed good adherence.

Only a small minority discontinued therapy because of side effects and reported side effects were mild.

The results of our study suggest that early initiation of statin therapy may contribute to habitual use of medication despite its preventive character. 


\section{Introduction}

Familial hypercholesterolemia (FH), a common dominantly inherited disorder of lipoprotein metabolism, is characterized by severely elevated low-density lipoprotein cholesterol (LDL-C) levels from birth onwards that predispose to premature atherosclerosis and subsequent cardiovascular disease (CVD) $[1,2]$. In order to protect FH children from premature CVD, statins are currently the preferred pharmacological therapy and are recommended from the age of 8 years onwards [3,4]. The efficacy of statins in this patient group was recently underlined by the results of a 10-year follow-up study in young adults with FH that showed that long-term statin treatment was associated with normalization of progression of the carotid intima media thickness (cIMT), a marker of early atherosclerosis [5]. However, LDL-C levels of the majority of patients in this study did not meet current treatment standards.

Studies among middle-aged hypercholesterolemic patients reported that a significant number do not achieve LDL-C goals, mainly due to poor adherence to statin therapy [6-8]. It could be hypothesized that young FH patients might be even less adherent since several studies among individuals with other chronic disorders reported poor adherence during adolescence, a stage of life in which both development and social context change simultaneously [9-11]. Furthermore, in FH individuals, young patients are asymptomatic and less likely to perceive themselves at risk for CVD, which could lead to poor adherence. Lastly, statin intolerance, or the inability to use statins because of side effects, might cause poor adherence or even discontinuation of treatment.

Little is known about tolerability and adherence in young FH patients and we therefore set out to study these characteristics in a cohort of young adult FH patients after 10 years of statin therapy that was initiated in childhood. Furthermore, we also examined the association between patient characteristics and adherence. Here, we present our results.

\section{Methods}

\subsection{Study Population and Design}

All 214 children who were randomized between 1997 and 1999 into a single-center, double-blind, placebo-controlled trial, evaluating the efficacy and safety of pravastatin, were eligible for the current study. The trial has been described in detail elsewhere [5, 12]. Briefly, children were enrolled in that study when they met the following criteria: one parent with a definite clinical or molecular diagnosis of $\mathrm{FH}$; age between 8 and 18 years; at least 3 months on a fatrestricted diet; two fasting samples with plasma LDL-C levels $\geq 4.0 \mathrm{mmol} / \mathrm{L}$ and triglyceride levels $<4.0 \mathrm{mmol} / \mathrm{L}$; adequate contraception in sexually active girls; and no drug treatment for $\mathrm{FH}$ or use of plant sterols. Reasons for exclusion were homozygous $\mathrm{FH}$, hypothyroidism, and abnormal plasma levels of muscle or liver enzymes. Children were randomly assigned to receive either pravastatin or placebo for 2 years. In the active treatment group, children younger than 14 years of age received $20 \mathrm{mg}$ of pravastatin, and those aged 14 years or older received $40 \mathrm{mg}$ daily. After the end of the placebo-controlled trial, pravastatin was given to both treatment groups $(<14$ years: $20 \mathrm{mg}, \geq 14$ years: $40 \mathrm{mg}$ ). Children were subsequently seen at our outpatient clinic until referral to an adult lipid clinic or general practitioner for further follow-up.

Ten years after the trial was initiated, we sent all FH patients a letter that explained the study design of the current 10-year follow-up study and announced a phone call within a month. The research physician contacted all FH patients. Patients who did not agree to participate were asked for their reasons for non-participation and those patients who did agree were invited for a single visit to the Academic Medical Center. One week before this visit we sent patients a questionnaire including items about medical history, family history, adherence, reasons for discontinuation, and adverse events. Patients were asked to fill out the questionnaire at home and take it along to their visit. During this visit the patients were physically examined (height, weight, blood pressure) and a fasted blood sample was taken. The protocol of the study was approved by the Institutional Review Board and all patients gave informed consent.

\subsection{Blood Analyses}

In the fasted blood sample, total cholesterol, high-density lipoprotein cholesterol (HDL-C) and triglyceride levels were determined by means of commercially available kits (Boehringer, Mannheim, Germany). Levels of LDL-C were calculated with the Friedewald equation [13].

\subsection{Outcome Measures}

The outcome measures in the current study were tolerability and self-reported adherence to statin therapy after 10 years of treatment. Tolerability was defined as follows: $100 \%$ minus the percentage of patients that discontinued statin therapy because of side effects. Adherence was defined as the extent to which patients took their medication as prescribed by their physician. We assessed 
adherence using the Medication Adherence Self-Report Inventory (MASRI) and the Medication Adherence Report Scale (MARS), which have been found to have good reliability and validity and were previously used in patients with FH [14-16]. Of the MASRI questionnaire, we used the visual analog scale (VAS) items to determine a numeric estimate of the adherence rate $(0-100 \%)$ in the preceding week, month, and year. We labelled patients adherent if they took $80 \%$ or more of their lipid-lowering drugs in the preceding month [17]. The MARS consists of five statements describing non-adherent behavior: 'I forget to take my cholesterol-lowering medication', 'I alter the dose of my cholesterol-lowering medication', 'I stop taking my cholesterol-lowering medication for a while', 'I decide to miss out a dose of my cholesterol-lowering medication', and 'I take less cholesterol-lowering medication than instructed'. Respondents indicate their degree of agreement with each statement about medicine taking on a 5-point Likert scale, ranging from always (1) to never (5). Sum scores range between 5 and 25 points, with higher scores indicating higher levels of adherence.

\subsection{Statistical Analysis}

Continuous variables between subgroups were compared using the independent sample- $t$ test. Variables with a skewed distribution were compared by the non-parametric Mann-Whitney $U$ test. Chi-square tests were applied for comparing distributions of dichotomous data. We first explored the association between adherence (yes or no) to statin therapy after 10 years of treatment and the patient characteristics (i.e., age, gender, body mass index, LDL-C at statin initiation, and presence of first degree family history of CVD), medication use besides lipid-lowering medication, whether medication was initiated before puberty (defined as before the age of 11.5 years for girls, and before the age of 13.5 years for boys), and reported side effects, by means of logistic regression analysis. A multivariable model was used to evaluate the independent contributions to the prediction of adherence (yes or no). Inclusion in the final model was determined by backward stepwise elimination. A two-sided $p$ value of 0.05 was considered to indicate statistical significance. All data were analyzed with SPSS software (version 18.0; SPSS Inc, Chicago, IL, USA).

\section{Results}

\subsection{Population Characteristics}

From the original patient cohort of 214 children, nine subjects $(4.2 \%)$ were not available for follow-up because they refused consent $(n=5)$ or had moved abroad $(n=2)$, and one male adolescent had died after a motorcycle accident (Fig. 1). One male was excluded, because he had not completed the questionnaire. Of the remaining 205 subjects, the mean age $[ \pm$ standard deviation $(\mathrm{SD})]$ was
Fig. 1 Flow chart of familial hypercholesterolemia $(\mathrm{FH})$ patients enrolled in the study

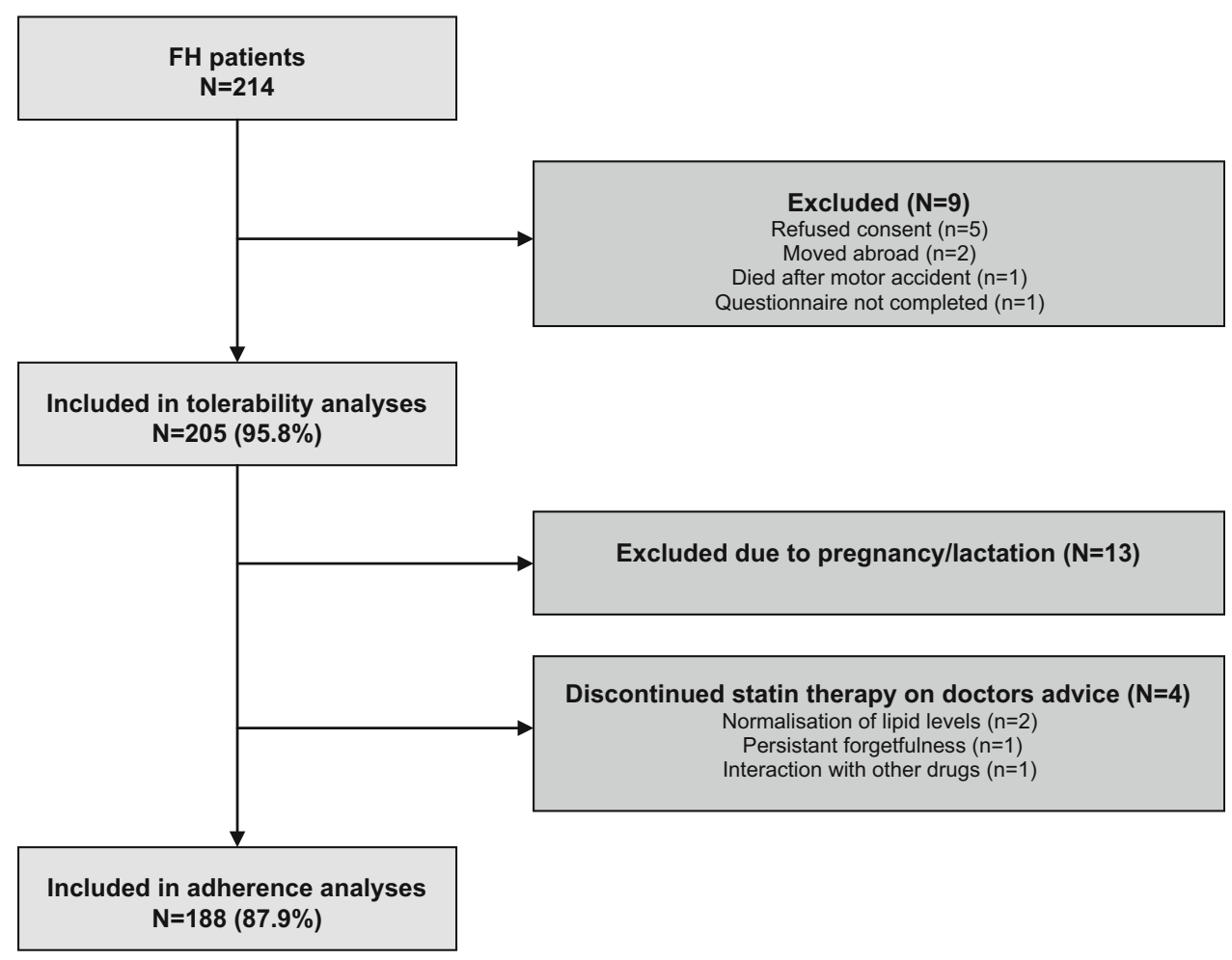


Table 1 Patient characteristics and lipid profile in 205 patients with familial hypercholesterolemia at the start of the randomized clinical trial and at 10 -year follow-up

\begin{tabular}{lll}
\hline & Start of RCT & End of follow-up \\
\hline Age (years) & $13.0(2.9)$ & $24.0(3.2)$ \\
Initiation before puberty, n (\%) & $82(38.3)$ & $79(38.5)$ \\
Male gender, n (\%) & $100(47)$ & $94(46)$ \\
Height $(\mathrm{cm})$ & $156.3(14.8)$ & $173.1(13.4)$ \\
Weight $(\mathrm{kg})$ & $49.2(15.3)$ & $74.0(14.6)$ \\
Body mass index $\left(\mathrm{kg} / \mathrm{m}^{2}\right)$ & $19.6(3.6)$ & $24.5(4.7)$ \\
Blood pressure $(\mathrm{mmHg})$ & & $126(12)$ \\
Systolic & $110(12)$ & $75(8)$ \\
Diastolic & $62(9)$ & $89(15)$ \\
Mean arterial blood pressure & $78(8)$ & \\
Lipids (mmol/L) & & $6.24(1.79)$ \\
Total cholesterol & $7.78(1.35)$ & $4.48(1.71)$ \\
LDL cholesterol & $6.13(1.31)$ & $1.30(0.33)$ \\
HDL cholesterol & $1.24(0.28)$ & $0.89[0.68-1.18]$ \\
Triglycerides & 0.76 & \\
& {$[0.55-1.09]$} &
\end{tabular}

Values are given as mean levels (standard deviation) or otherwise indicated. Triglycerides are given as median [interquartile range]

$H D L$ high-density lipoprotein, $L D L$ low-density lipoprotein, $R C T$ randomized clinical trial

$24.0( \pm 3.2)$ years and $45.9 \%$ were male. Furthermore, 76 patients $(37.1 \%)$ had a family history with CVD in a firstdegree relative. Demographic characteristics and lipid profiles at the start of the randomized trial and after followup are depicted in Table 1.

Lipid-lowering therapy was still used by $169(82.4 \%)$ subjects. Of these, 105 (62.1\%) used statin monotherapy and another 63 subjects $(37.3 \%)$ used statins in combination with other lipid-lowering drugs, either ezetimibe $(n=61)$ or cholestagel $(n=2)$. One subject received cholestagel monotherapy. Of the patients using statins, the majority were still on pravastatin $(29.6 \%)$ or had switched to atorvastatin (28.4\%) (Table 2).

None of the subjects had cardiovascular complaints or a cardiovascular event during follow-up. The mean $( \pm \mathrm{SD})$ number of follow-up visits after the initial trial at the outpatient clinic by either a (local) lipidologist or general practitioner was $9.9( \pm 4.6)$.

\subsection{Tolerability}

Three out of 205 patients had completely discontinued drug therapy due to side effects; i.e., a tolerability of $98.5 \%$. All three patients reported a combination of gastro-intestinal symptoms, muscle and joint pain, or headache. Overall, 55 side effects were reported in the last 10 years by 40
Table 2 Statin type and dosage in 167 familial hypercholesterolemia patients

\begin{tabular}{|c|c|c|c|}
\hline $\begin{array}{l}\text { Type of } \\
\text { statin }\end{array}$ & $\begin{array}{l}\text { Statin } \\
\text { monotherapy } \\
(n=105)\end{array}$ & $\begin{array}{l}\text { Statin }+ \\
\text { ezetimibe } \\
(n=61)\end{array}$ & $\begin{array}{l}\text { Statin }+ \\
\text { cholestagel } \\
(n=2)\end{array}$ \\
\hline \multicolumn{4}{|c|}{ Simvastatin $(n=26)$} \\
\hline $10 \mathrm{mg}$ & - & 2 & - \\
\hline $20 \mathrm{mg}$ & 4 & 3 & - \\
\hline $40 \mathrm{mg}$ & 5 & 11 & - \\
\hline $80 \mathrm{mg}$ & - & 1 & - \\
\hline \multicolumn{4}{|c|}{ Pravastatin $(n=50)$} \\
\hline $20 \mathrm{mg}$ & 17 & 2 & - \\
\hline $40 \mathrm{mg}$ & 26 & 3 & - \\
\hline $80 \mathrm{mg}$ & 1 & 1 & - \\
\hline \multicolumn{4}{|c|}{ Rosuvastatin $(n=44)$} \\
\hline $10 \mathrm{mg}$ & 7 & 4 & - \\
\hline $20 \mathrm{mg}$ & 13 & 7 & - \\
\hline $40 \mathrm{mg}$ & 7 & 6 & - \\
\hline \multicolumn{4}{|c|}{ Atorvastatin $(n=48)$} \\
\hline $10 \mathrm{mg}$ & 1 & - & - \\
\hline $20 \mathrm{mg}$ & 7 & 6 & - \\
\hline $40 \mathrm{mg}$ & 15 & 11 & - \\
\hline $80 \mathrm{mg}$ & 2 & 4 & 2 \\
\hline
\end{tabular}

subjects (19.5\%), mainly consisting of muscle complaints in 19 patients $(9.3 \%)$ and gastrointestinal symptoms in 14 patients $(6.8 \%)$ (Fig. 2). No major side effects, such as rhabdomyolysis or elevation of liver enzymes, were reported.

\subsection{Adherence}

Current practice is to advise pregnant women with $\mathrm{FH}$ to discontinue all systematically absorbed lipid-lowering medication; we therefore decided to exclude those patients who discontinued statin therapy due to current pregnancy or lactation $(n=13)$ from the analyses on adherence. Furthermore, we also excluded four patients who discontinued on the request of their physician. Reasons for those discontinuations were normalization of lipid levels $(n=2)$, interaction with other drugs $(n=1)$ and persistent forgetfulness to take medication (Fig. 1). Of the remaining study group of 188 subjects, 169 patients $(89.9 \%)$ used lipid-lowering medication.

In these $169 \mathrm{FH}$ patients, median [IQR] self-reported adherence by VAS over the preceding week, month, and year was $100 \%$ [90-100\%], $95 \%$ [87-100\%] and $90 \%$ [80-100\%], respectively. Adherence to lipid-lowering therapy, defined as taking $80 \%$ or more of the prescribed drugs in the last month, was reported by 148 out of 188 $(78.7 \%)$ subjects. Adherent patients had significantly lower mean (SD) total cholesterol $(5.55 \pm 1.12$ vs 
Fig. 2 Number of patients that had ever experienced side effects in the last 10 years. Other: frequent urination $(2 \times)$, weight reduction, hair loss, forgetfulness

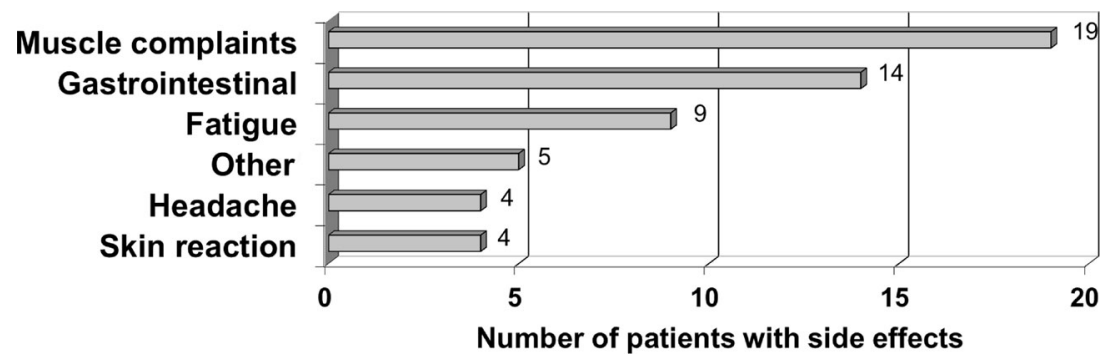

Table 3 Lipid profile of adherent and non-adherent familial hypercholesterolemia subjects

\begin{tabular}{lllc}
\hline Lipids (mmol/L) & $\begin{array}{l}\text { Adherent } \\
(n=148)\end{array}$ & $\begin{array}{l}\text { Non-adherent } \\
(n=40)\end{array}$ & $p$ value \\
\hline Total cholesterol & $5.55(1.12)$ & $7.81(1.92)$ & $<0.001$ \\
LDL cholesterol & $3.85(1.03)$ & $6.00(1.91)$ & $<0.001$ \\
HDL cholesterol & $1.29(0.35)$ & $1.26(0.28)$ & 0.62 \\
Triglycerides & $0.84[0.64-1.04]$ & $0.95[0.74-1.26]$ & $<0.001$ \\
\hline
\end{tabular}

Values are given as mean levels (standard deviation) or otherwise indicated. Triglycerides are given as median [interquartile range]

$H D L$ high-density lipoprotein, $L D L$ low-density lipoprotein

$7.81 \pm 1.92 \mathrm{mmol} / \mathrm{L}, p<0.001)$, LDL-C $(3.85 \pm 1.03$ vs $6.00 \pm 1.91 \mathrm{mmol} / \mathrm{L}, p<0.001)$ and median (IQR) triglyceride levels $(0.84$ [0.64-1.04] vs 0.95 [0.74-1.26] $\mathrm{mmol} / \mathrm{L}, \quad p<0.001$ ), compared with the non-adherent group. HDL-C levels did not differ significantly $(1.29 \pm 0.35$ vs $1.26 \pm 0.28 \mathrm{mmol} / \mathrm{L}, p=0.62)$ between adherent and non-adherent patients (Table 3). In addition, adherent patients came more frequently to the follow-up visits as compared with the non-adherent subjects after the original trial [mean (SD): $10.5 \pm 4.5$ and $7.6( \pm 4.3)$ visits; $p=0.001$, respectively].

Out of the 40 non-adherent subjects (defined as taking less than $80 \%$ of the prescribed drugs in the last month), 15 patients took between $50 \%$ and $75 \%$ of their medication. Furthermore, 19 patients $(9.3 \%)$ had completely discontinued statin therapy. Reasons for discontinuation were as follows: forgotten to take medication $(n=8)$, unwillingness to take any medication $(n=6)$, and side effects $(n=3)$. Reasons for discontinuation of therapy for two patients were unknown.

The results of univariate analysis of the association between adherence and patient characteristics are shown in Table 4. No significant associations between any of the patient characteristics and adherence to statin therapy were found. Also, in the multivariable analyses after backward elimination, none of the variables appeared to be independently associated with adherence.

More insight in non-adherent behavior was obtained with MARS questionnaires, consisting of five items on nonadherent behavior. Responses were skewed with a median
Table 4 Association between patient characteristics and adherence to statin therapy 10 years after initiation of statin therapy

\begin{tabular}{lll}
\hline & $\begin{array}{l}\text { Univariate OR } \\
(95 \% \mathrm{CI})\end{array}$ & $p$ value \\
\hline Age (years) & $1.11(0.97-1.22)$ & 0.17 \\
Male gender & $1.28(0.63-2.61)$ & 0.49 \\
$\begin{array}{l}\text { Body mass index }\left(\mathrm{kg} / \mathrm{m}^{2}\right) \\
\text { LDL cholesterol (pre-statin) }\end{array}$ & $0.96(0.89-1.03)$ & 0.25 \\
$\quad(\mathrm{mmol} / \mathrm{L})$ & $0.90(0.70-1.19)$ & 0.50 \\
CVD first-degree family & $1.20(0.58-2.46)$ & 0.62 \\
$\begin{array}{l}\text { Use of medication other } \\
\text { than statins }\end{array}$ & $1.39(0.49-3.90)$ & 0.54 \\
$\begin{array}{l}\text { Initiation of statin therapy } \\
\text { before puberty }\end{array}$ & $1.66(0.77-3.58)$ & 0.20 \\
Side effects & $0.54(0.31-1.87)$ & 0.54 \\
\hline
\end{tabular}

$B M I$ body mass index, $C V D$ cardiovascular disease, $L D L$ low-density lipoprotein, $O R(95 \% C I)$ odds ratio (95\% confidence interval)

score of 24 (range 5-25); $16.4 \%$ scored 25 (i.e., highly adherent), $35.3 \%$ scored 24 and $40.4 \%$ scored 23 or less. Five subjects stated that they always forgot to take their medication and that they always stopped their medication for a while. Three subjects stated that they always take less medication than prescribed. On the question "I change the dose prescribed", one participant answered "always true", and on the question "I decide to skip a dose", two patients indicated this statement to be always true.

\section{Discussion}

The current study is the first study that assessed tolerability and adherence of young adult FH patients after long-term statin therapy that was initiated in childhood. Our findings indicated that statin therapy was well tolerated; only a small minority $(1.5 \%)$ discontinued therapy because of side effects and reported side effects were in fact mild. The vast majority of patients $(82.4 \%)$ continued lipid-lowering therapy, with a high self-reported adherence rate of $78.7 \%$. None of the patient characteristics were significantly associated with adherence.

The use of statin treatment for the prevention of CVD in patients with $\mathrm{FH}$ is supported by extensive clinical 
evidence, and the data highlight the safety and tolerability of statins [18]. Our present study is the longest follow-up study of patients treated with statins. A follow-up rate as high as $95.8 \%$ was achieved and patient characteristics of the non-participants $(n=9)$ did not differ significantly from those of the 205 participants at the start of the randomized trial period. No major side effects like elevation of liver enzymes or rhabdomyolysis had occurred. Analyses by the FDA have reported a rate of fatal rhabdomyolysis of 0.15 per one million statin prescriptions; therefore, our present sample size is too small to draw conclusions on the occurrence of rhabdmyolysis or other serious adverse events [19].

The most frequently discussed side effects of statin therapy are muscle-related complaints. In our study, we found $9.3 \%$ of the FH patients have reported to have ever experienced muscle complaints. Studies on myopathy related to long-term statin therapy in young adult FH patients have not been previously reported. Our results are, however, in line with a large observational study of 7,924 hyperlipidemic patients on high-dose statins in general practice, aged 18-75 years (PRIMO study). This study reported an incidence of $10.5 \%$ of mild muscular symptoms in the first months after statin therapy was initiated. These patients were using high doses of statins which increase the risk of muscular complaints [20]. Two reviews of more than 35 published clinical trials on patients taking different kinds of statins reported lower incidences of myalgia of $1-5 \%$, which was not significantly different from the incidence in their placebo group [19, 21]. Inclusion criteria in these statin studies are quite stringent and patients with a medical history of statin-related side effects might have been excluded from participation resulting in a low incidence of myalgia. Mean duration of follow-up varied extensively between these studies and no consistent and uniformly applied definition was used; therefore, these results on muscle-related side effects are difficult to compare with our study. Furthermore, we used questionnaires to get insight into muscle-related side effects due to statin treatment. Also, the average age of our patient cohort is relatively young compared with most other studies and therefore the patients in our study might be more active and practising sports and subsequently experience more muscle complaints.

Adherence to and persistence with statin therapy is crucial in the management of patients at risk for CVD, since good adherence and longer duration of persistence are associated with increasing clinical benefits [22-24]. In general, persistence rates among patients with chronic conditions such as $\mathrm{FH}$ are quite low, decreasing mainly in the first 6 months of therapy [25-27]. In our study, 10 years after the start of statin treatment, we found a remarkably high adherence rate of $78.7 \%$, defined as those for whom $80 \%$ or more of days in the last month were covered by statin therapy. This was further supported by a high median score of 24 (range 5-25) on MARS statements, indicating that only very few patients showed nonadherent behavior. Other long-term follow-up studies evaluating adherence to statin therapy in primary prevention indicated adherence rates as low as $39 \%$ after 3 years of treatment. These trials have been conducted in elderly non-FH patients, who initiated treatment at the mean age of 56 years and older [26, 27]. These results are therefore difficult to compare with our young adult population using statins as primary prevention from childhood onwards. Our study subjects initiated statin therapy in childhood during a clinical trial, with regular visits (i.e., every 3 months) to our outpatient clinic. This early initiation of treatment and close monitoring might contribute to habitual use of statins and therefore better adherence to therapy. However, patients' self-reported statin use was acquired to determine their adherence. This method might be susceptible to inaccurate patient recall or social desirability and might lead to an overestimation of adherence. However, adherent patients had significantly lower cholesterol levels than nonadherent patients, an effect that cannot be explained by a difference in untreated cholesterol levels.

As in all randomized controlled trials, stringent inclusion and exclusion criteria were applied, essentially excluding the sickest and frailest people, which could limit the generalizability of our results. However, FH children were enrolled in the trial between 1997 and 1999 and at that time the Academic Medical Center was the only clinic in The Netherlands and one of the very few clinics worldwide that treated these children. As a consequence, children with FH were referred from all over the country to our lipid clinic and from that point of view the children included in our study are a reasonable representative of the general population with this disorder.

The main reason for discontinuation of therapy in our study group was pregnancy, which is in accordance to current medical advice. Non-adherence in our cohort was accompanied by significantly higher LDL-C levels and a lower out-patient follow-up frequency. Reasons for nonadherence were unwillingness to take medication and forgetfulness. According to the literature, non-adherence is associated with younger age, female gender, lower socioeconomic status and complex treatment regimen [6, 28, 29]. Although we did not have information on socio-economic status, our results did not reveal significant associations between these or any of the other factors and adherence to statin therapy.

Current practice in $\mathrm{FH}$ patients is to achieve LDL-C reduction of at least $50 \%$ and preferably LDL-C levels below $2.5 \mathrm{mmol} / \mathrm{L}$ [30]. Neither of these treatment goals have been reached in our study group. Despite a good 
adherence rate of $78.7 \%$ in our cohort, the mean LDL-C level of the adherent group was still $3.85 \mathrm{mmol} / \mathrm{L}$, and only eight patients had LDL-C levels $<2.50 \mathrm{mmol} / \mathrm{L}$. Our results are in line with those of Pijlman et al. [31], who conducted a cross-sectional study among adult FH patients in the Netherlands and concluded that only $21 \%$ of the 1,249 patients reached the treatment goal for LDL-C of $<2.5 \mathrm{mmol} / \mathrm{L}$. This raises serious concerns on the risk of future cardiovascular events and therefore treatment regimens for this patient group should be improved in the future.

In conclusion, this study demonstrates that patients with FH who started statin therapy in childhood, regardless whether this was before or after puberty, showed good adherence during 10 years of treatment. The fact that early initiation may contribute to habitual use of medication despite its preventive character, and the fact that none of the patients had suffered from cardiovascular disease are important clinical findings. Even more important, statin therapy was very well tolerated; only a very small minority discontinued therapy because of side effects, and reported side effects were mild. However, their treatment appeared to be suboptimal in terms of efficacy and this merits further attention.

Funding Source of funding: the AfterTen study is supported by the Dutch Heart Foundation [2009B059].

Conflicts of interest J.J.P.K. is a consultant to and receives honoraria from AstraZeneca, Eli Lilly, Amgen, Sanofi, Regeneron, Genzyme, Isis, Aegerion and KOWA. J.J.P.K. is a recipient of the Lifetime Achievement Award of the Dutch Heart Foundation [2010T082].

Open Access This article is distributed under the terms of the Creative Commons Attribution Noncommercial License which permits any noncommercial use, distribution, and reproduction in any medium, provided the original author(s) and the source are credited.

\section{Reference}

1. Marks D, Thorogood M, Neil HAW, Humphries SE. A review on the diagnosis, natural history, and treatment of familial hypercholesterolaemia. Atherosclerosis. 2003;168(1):1-14.

2. Goldstein JL, Hobbs HH, Brown MS. PART 12: LIPIDS Chapter 120: Familial Hypercholesterolemia Joseph L. Goldstein, Helen H. Hobbs, Michael S. Brown. In: Scriver CR, Beaudet AL, Sly WS, Valle D, editors. The Metabolic and Molecular Bases of Inherited Disease. 8th ed.; 2001. p. 2863-2913.

3. Daniels SR. Screening and treatment of dyslipidemias in children and adolescents. Horm Res Paediatr. 2011;76(suppl 1):47-51. doi:10.1159/000329163.

4. McCrindle BW, Urbina EM, Dennison BA, et al. Drug therapy of high-risk lipid abnormalities in children and adolescents: a scientific statement from the American Heart Association Atherosclerosis, Hypertension, and Obesity in Youth Committee,
Council of Cardiovascular Disease in the Young, with the C. Circulation. 2007;115(14):1948-67.

5. Kusters DM, Avis HJ, de Groot E, et al. Ten-year follow-up after initiation of statin therapy in children with familial hypercholesterolemia. JAMA. 2014;312(10):1055-7. doi:10.1001/jama. 2014.8892.

6. Ho PM, Bryson CL, Rumsfeld JS. Medication adherence: its importance in cardiovascular outcomes. Circulation. 2009;119(23):3028-35.

7. Huijgen R, Kindt I, Verhoeven SBJ, et al. Two years after molecular diagnosis of familial hypercholesterolemia: majority on cholesterol-lowering treatment but a minority reaches treatment goal. PLoS One. 2010;5(2):e9220.

8. Osterberg L, Blaschke T. Adherence to medication. N Engl J Med. 2005;353(5):487-97.

9. Kovacs M, Goldston D, Obrosky DS, Bonar LK. Psychiatric disorders in youths with IDDM: rates and risk factors. Diabetes Care. 1997;20(1):36-44.

10. Nachega JB, Hislop M, Nguyen H, et al. Antiretroviral therapy adherence, virologic and immunologic outcomes in adolescents compared with adults in southern Africa. J Acquir Immune Defic Syndr. 2009;51(1):65-71.

11. Zindani GN, Streetman DD, Streetman DS, Nasr SZ. Adherence to treatment in children and adolescent patients with cystic fibrosis. J Adolesc Health. 2006;38(1):13-7.

12. Wiegman A, Hutten BA, de Groot E, et al. Efficacy and safety of statin therapy in children with familial hypercholesterolemia: a randomized controlled trial. JAMA. 2004;292(3):331-7. doi:10. 1001/jama.292.3.331.

13. Friedewald WT, Levy RI, Fredrickson DS. Estimation of the concentration of low-density lipoprotein cholesterol in plasma, without use of the preparative ultracentrifuge. Clin Chem. 1972;18(6):499-502.

14. Senior V, Marteau TM, Weinman J. Self-reported adherence to cholesterol-lowering medication in patients with familial hypercholesterolaemia: the role of illness perceptions. Cardiovasc Drugs Ther. 2004;18(6):475-81.

15. Cohen JL, Mann DM, Wisnivesky JP, et al. Assessing the validity of self-reported medication adherence among inner-city asthmatic adults: the Medication Adherence Report Scale for Asthma. Ann Allergy Asthma Immunol. 2009;103(4):325-31.

16. Horne R, Parham R, Driscoll R, Robinson A. Patients' attitudes to medicines and adherence to maintenance treatment in inflammatory bowel disease. Inflamm Bowel Dis. 2009;15(6):837-44.

17. Bell KJL, Kirby A, Hayen A, Irwig L, Glasziou P. Monitoring adherence to drug treatment by using change in cholesterol concentration: secondary analysis of trial data. BMJ. 2011;342:d12.

18. Baigent C, Keech A, Kearney PM, et al. Efficacy and safety of cholesterol-lowering treatment: prospective meta-analysis of data from 90,056 participants in 14 randomised trials of statins. Lancet. 2005;366(9493):1267-78.

19. Thompson PD, Clarkson P, Karas RH. Statin-associated myopathy. JAMA. 2003;289(13):1681-90.

20. Bruckert E, Hayem G, Dejager S, Yau C, Bégaud B. Mild to moderate muscular symptoms with high-dosage statin therapy in hyperlipidemic patients - the PRIMO study. Cardiovasc Drugs Ther. 2005;19(6):403-14.

21. Kashani A, Phillips CO, Foody JM, et al. Risks associated with statin therapy: a systematic overview of randomized clinical trials. Circulation. 2006;114(25):2788-97.

22. Perreault S, Dragomir A, Blais L, et al. Impact of better adherence to statin agents in the primary prevention of coronary artery disease. Eur J Clin Pharmacol. 2009;65(10):1013-24.

23. Perreault S, Ellia L, Dragomir A, et al. Effect of statin adherence on cerebrovascular disease in primary prevention. Am J Med. 2009;122(7):647-55. 
24. Bouchard M-H, Dragomir A, Blais L, Bérard A, Pilon D, Perreault $\mathrm{S}$. Impact of adherence to statins on coronary artery disease in primary prevention. Br J Clin Pharmacol. 2007;63(6):698-708.

25. Benner JS, Glynn RJ, Mogun H, Neumann PJ, Weinstein MC, Avorn J. Long-term persistence in use of statin therapy in elderly patients. JAMA. 2002;288(4):455-61.

26. Jackevicius CA, Mamdani M, Tu JV. Adherence with statin therapy in elderly patients with and without acute coronary syndromes. JAMA. 2002;288(4):462-7.

27. Perreault S, Blais L, Dragomir A, et al. Persistence and determinants of statin therapy among middle-aged patients free of cardiovascular disease. Eur J Clin Pharmacol. 2005;61(9):667-74.

28. Mann DM, Woodward M, Muntner P, Falzon L, Kronish I. Predictors of nonadherence to statins: a systematic review and meta-analysis. Ann Pharmacother. 2010;44(9):1410-21.
29. Simpson RJ, Mendys P. The effects of adherence and persistence on clinical outcomes in patients treated with statins: a systematic review. J Clin Lipidol. 2010;4(6):462-71.

30. Goldberg AC, Hopkins PN, Toth PP, et al. Familial hypercholesterolemia: screening, diagnosis and management of pediatric and adult patients: clinical guidance from the National Lipid Association Expert Panel on Familial Hypercholesterolemia. J Clin Lipidol. 2011;5(3):133-40.

31. Pijlmana H, Huijgen R, Verhagen SN, et al. Evaluation of cholesterol lowering treatment of patients with familial hypercholesterolemia: a large cross-sectional study in The Netherlands. Atherosclerosis. 2010;209(1):189-94. 